\title{
Nudging and environmental corporate responsibility: A natural experiment
}

\author{
Leonardo Becchetti* $\quad$ Francesco Salustri ${ }^{\dagger} \quad$ Pasquale Scaramozzino ${ }^{\ddagger}$ \\ - This draft: 8 May 2017 -
}

\begin{abstract}
We devise a 'nudging' natural experiment to test the impact of a simple form of advertising on environmentally responsible products with/without the increase of the responsible product price. We find that the simple use of a small shelf-poster explaining the importance of buying a green product (with/without a concurring price increase) generates significant changes in market shares for some of the product classes for both food and non-food products. Part of the effect is generated by the reduced price elasticity of consumers to the poster-plus-price-increase treatment.
\end{abstract}

Keywords: nudging, environmental sustainability, randomised field experiment.

JEL Classification: C93 (Field experiments), D12 (Consumer economics: empirical analysis), M14 (Corporate culture; Social Responsibility), Q56 (Environment and Development; Sustainability)

\section{Introduction}

The role of nudging as a new and original policy solution to pursue socially optimal goals has recently started being investigated by the behavioural economic literature. In this paper we devise a natural nudging experiment aimed at stimulating environmentally responsible behaviour, and discuss how our experimental framework provides a novel contribution to the research fields of nudging and environmental sustainability.

As is well known, Pigou taxes and regulation have been classically considered as two possible solutions to environmental market failures in the literature but their actual implementation presents several problems. Beyond the difficulties and costs of measuring properly the distance between producer private optimum and social optimum, and/or of enforcing proper regulation, the picture becomes even more complex in globalised economies where a tax which raises the cost of pollution in one country may produce delocalisation and 'race to the bottom' of companies looking for the cheapest environmental production costs. The recent literature on green nudges

\footnotetext{
${ }^{*}$ Corresponding author. Dept. of Economics and Finance, University of Rome Tor Vergata, via Columbia, 2 - 00133 Rome. Email: becchetti@economia.uniroma2.it.

${ }^{\dagger}$ Dept. of Economics and Finance, University of Rome Tor Vergata. Email: francesco.salustri@uniroma2.it.

${ }^{\ddagger}$ School of Finance and Management, SOAS University of London, and Dept. of Economics and Finance, University of Rome Tor Vergata. Email: ps6@soas.ac.uk.
} 
(Schubert, 2016) suggests that a libertarian paternalistic approach on the demand side which slightly modifies the frame in which agents' choices occur may contribute to solve the problem with very limited costs for policymakers. Our natural experiment proposes a typical green nudge consisting of a small poster advertising the importance of buying an environmentally responsible product (see Figure 1). The small poster is strategically placed in a selected group of supermarkets on the shelves where products can be found replacing the traditional price tag. ${ }_{-}^{1}$

Our experiment falls within the nudging definition since, contrary to incentive based measures, it keeps intact the choice set and the monetary incentives of players. As well, the strategic placement of the poster and the emphasis on the importance of buying an environmentally responsible product are two features that go beyond the neutral information provision (Schubert, 2016).

The experiment also shares with the nudging approach the paternalistic libertarian vision, even though with some specific qualifications. It is paternalistic since it aims at improving the environment and, through it, the wellbeing of players, consistently with the 'paternalistic' definition of Thaler and Sustein (2003). ${ }^{2}$ As we explain in section 2, if we make reference to the vote with the wallet literature (Becchetti and Salustri, 2015) the choice of a green responsible product against the conventional alternative falls into the class of multiplayer prisoner's dilemmas: a coordinated vote with the wallet of all players choosing the responsible vis a vis the conventional (cheaper) product makes all of them better off, even though the dominant strategy for each individual is to choose the conventional product. In this sense our experiment falls better into the welfarian paternalistic nudging category than into the strictly paternalistic nudging category. That is, given the typical coordination failure problem of the above sketched social dilemma, the suggested choice does not per se improve agent's wellbeing if the agent's choice is not followed also by similar choices by the other agents.

Another interesting element in the definition of our nudging experiment is related to the issue of agents' preference assumptions. As is well known there is a strict connection in the literature between nudging and bounded rationality. In essence, nudging can produce significant changes in players' action by only using slight frame changes if agents are 'humans' and not 'Econs', that is, if they suffer from some forms of irrationality by which the nudge can modify their utility and their choices, even in absence of changes of monetary incentives in the choice set. ${ }^{3}$ Our reference to the vote with the wallet model suggests a slightly different story here where nudging does not need to be inevitably related to bounded rationality. The nudge represented by the label may in fact have two effects that modify choices of fully rational agents even without changing monetary incentives of the choice set. First, the nudge can reinforce their beliefs on the environmentally sustainable features of the product, thereby reducing informational asymmetries in this specific domain (see the model in the Appendix). Players therefore choose the environmental product because they are more convinced than before about its characteristics that in turn satisfy the other-regarding component (if any) of their preferences. Second, the nudge can change players' expectation on the choice of the other players (see Appendix). This aspect is crucial in the vote with the wallet multiplayer prisoner's dilemma structure. Players may have in fact reciprocity arguments (Rabin, 1993) that typically explain conditional cooperation in aggregate and make

\footnotetext{
${ }^{1}$ In this sense our experiment belongs to the same class of 'green nudging experiments' where, for instance, the 'no' button answer to the question about printing the ATM receipt is moved strategically to the right (the side of the screen where attention is more easily focused and the previous bottom had been pushed) and a message in green appears on the screen during cashing operations saying that not printing cash receipts is the 'advised choice'.

${ }^{2}$ "[The intervention] is selected with the goal of influencing the choices of affected parties in a way that will make those parties better off" (Thaler and Sunstein, 2003, p. 175).

${ }^{3}$ 'A nudge is any factor that significantly alters the behavior of Humans, even though it would be ignored by Econs" (emphasis added), where 'Econs' refers, basically, to homo economicus.
} 
it rational for them to cooperate (buy the responsible product) if all other players (or a number of players consistent with their expectations) cooperate, while making it rational to suspend cooperation if the share of cooperators falls. In this perspective the nudge (the label) may change players' expectation on the number of cooperators inducing them rationally to buy the responsible product.

In the literature we find few examples of experiments similar to ours showing that, while consumers attach value to ethical sourcing, there is significant heterogeneity in the willingness to pay for it. Hudson, Gallardo and Hanson (2012) analyse the capacity of a choice experiment to predict grocery store market shares, finding that the level of control in the grocery store experiment and the choice of econometric model influence results. Hainmueller, Hiscox and Sequeira (2014) find that sales of the two most popular coffees rose by almost $10 \%$ when they carried a Fair Trade label as compared to a generic placebo label. Demand for the higher priced coffee remained steady when its price was raised by $8 \%$, but demand for the lower priced coffee was elastic since a $9 \%$ price increase led to a $30 \%$ decline in sales. Hiscox, Broukhim and Litwin (2011) measure consumers' willingness to pay with an experiment conducted on eBay and document that shoppers paid a $23 \%$ premium for coffee labeled Fair Trade. More in general, and similarly to what is done in our experiment, other contributions have shown that reference to social norms has strong effects on pro-social behaviour (Griskevicius, Cialdini and Goldstein, 2006; Goldstein et al., 2008; Goldstein and Cialdini, 2009).

As we will remark below, under the assumption that consumption of some of the products on which our experiment is run does not significantly contribute to consumers' health, a significant effect of our treatment may be interpreted as contributing to the more general literature testing for the existence of other-regarding preferences. As is well known the quite ample literature in this field theoretically developed and empirically tested several concepts such as reciprocity (Rabin, 1993), inequity aversion (Fehr and Schmidt, 1999 and Bolton and Ockenfels, 2000), pure and impure altruism (Andreoni, 1989 and 1990) and social welfare preferences (Charness and Rabin, 2002). Most of the empirical evidence documented in this literature hinges on lab experiments and therefore the use of field experiments to test for the existence of other-regarding preferences is a clear added value, especially in terms of the external validity of the empirical findings.

Our experiment relates to the different strands of the literature mentioned in the introduction (nudging, other-regarding preferences, willingness to pay experiments) since we test for the first time the effect of a shelf poster treatment simultaneously applied to a wide range of green products. The empirical results of the paper show that the treatment has positive and significant effects on the market shares of a relevant part of the treated products. Part of the effects is related to the poster treatment per se, while part of them to consumers's price inelasticity in the poster plus price change treatments.

Our findings have straightforward policy implications. If public information on corporate environmental responsibility available at shopping places has a significant effect on customers, the provision of proper information and elicitation of consumers' environmental preferences may significantly help policymakers to achieve social and environmental goals at lower costs than what is the case with taxes or regulation.

The paper is divided into six sections. In the second section we present the experiment design. In the third section we outline our theoretical framework. In the fourth section we define our testable hypotheses, while in the fifth section we present and comment our empirical findings. 


\section{The experiment design}

In order to investigate the consumer demand for socially and environmentally responsible consumption, we conduct our field experiment in 12 Coop Italia (Coop) grocery stores. Coop is a system of Italian consumers' cooperatives operating the biggest Italian grocery store chain. ${ }^{4}$ Our analysis focuses on the Vivi Verde (VV) brand, a line of Coop products with a high ecological footprint. VV food products are organic products, and VV non-food products are 'EU Ecolabel' certified products or, more generally, environmentally sustainable labeled products.

During the treatment phases, we place a label on the shelves where VV products are located. The label is titled "Why buying Vivi Verde" and says: "This product comes from organic farming and has been projected and realised keeping into account its environmental impact. By purchasing this product at a fair price you are supporting environmentally responsible producer policies. A cleaner world is better also for you" (Figure 1). The first part of the message is the official product information also displayed on the Coop website. The second part highlights the positive externality of the purchase. The label is designed by the Coop marketing staff and is written in Italian. The title and the message display the same font size as the price and the product name respectively.

We create three types of treatments: the 'label' (Label), the 'label plus 5 percent price increase' (Label5), and the 'label plus 10 percent price increase' (Label10). In the Lab treatment, we introduce the shelf poster without changing product prices. In the Label5 treatment, we introduce the shelf poster and raise prices of the VV products by 5 percent. In the Label10 treatment, we introduce the shelf poster and raise prices of the VV products by 10 percent. For each treatment, we select 4 retail stores among those with the highest sales in the region of Tuscany where Coop mainly operates. We adopt a two-phase, two-group crossover design (Jones and Kenward 2003). We randomly pair the stores in 2 groups and randomly assign each group to a treatment-control sequence or viceversa, as shown in Table 2. Table 1 shows the randomisation checks for each type of treatment. ${ }_{-}^{6}$ Phase 1 takes place from 30 May to 26 June 2016, while phase 2 takes place from 27 June to 24 July $2016 ._{-}^{7}$ In addition, we monitor one treatment-free store that we consider as a parallel control store. The crossover design is more efficient than a simple parallel group design, because, if we assume no carry-over, it allows to exploit within-store variation for each store. The no carry-over assumption may be violated if consumers in the treatment-control sequence continue to choose products in phase 2 (control) because of information learned during phase 1. We rely on the fact that the violation of the no carry assumption provides a downward bias for the poster effect, since consumers who already know the information simply continue to be sensitive to the treatment even under the control condition. To check the no carry-over assumption, we perform two robustness checks that look at the last two weeks for each phase and that look at the stores belonging to group 2 (treatment-control sequence) only.

Table 1: Randomisation checks.

\begin{tabular}{|c|c|c|}
\hline & Treatment Group & Control Group \\
\hline \multicolumn{3}{|l|}{ Label Experiment } \\
\hline Total Store Sales 2015 & $€ 57,082,727.11$ & $€ 55,642,814.83$ \\
\hline \multicolumn{3}{|c|}{${ }^{4}$ In 2016 , Coop has the leadership among grocery retailers in Italy with a 10 percent share of sales valu } \\
\hline \multicolumn{3}{|c|}{$\begin{array}{l}\text { uromonitor International, 2016). } \\
{ }^{5} \mathrm{EU} \text { Ecolabel is a EU-recognised label that identifies products and services with a reduced environmenta } \\
\text { pact. For more information see http://ec.europa.eu/environment/ecolabel/. }\end{array}$} \\
\hline
\end{tabular}


Secondary Education (\% within the neighbourhood)

Foreign people (\% within the neighbourhood)

Relative Income $(100=$ household average $)$

\section{Label5 Experiment}

Total Store Sales 2015

Secondary Education (\% within the neighbourhood)

Foreign people (\% within the neighbourhood)

Relative Income $(100=$ household average $)$

Label10 Experiment

Total Store Sales 2015

Secondary Education (\% within the neighbourhood)

Foreign people (\% within the neighbourhood)

Relative Income $(100=$ household average $)$
60.42

59.90

9.90

10.75

96.02

93.20

$\begin{array}{cc}€ 88,618,570.12 & € 81,168,581.82 \\ 64.53 & 65.17 \\ 16.55 & 15.45 \\ 99.20 & 99.12 \\ & \\ € 70,204,034.89 & € 68,389,908.89 \\ 63.43 & 66.77 \\ 11.30 & 12.30 \\ 96.09 & 101.78\end{array}$

For our experiment, we select 22 out of $270 \mathrm{VV}$ products (Table 3). The logic of our selection is that of including products from a variety of classes, combining food and non-food products. Since consumers may want to buy a green product for environmental and/or health reasons we take care of having in our sample products that have different impact on consumers' health. More specifically, we include i) food products; ii) non-food products that may enter into contact with the human body (i.e., dish detergents and lip protectors); iii) non-food products that produce emissions that can be inhaled (such as surface cleaners) and iv) non-food products that do not enter in any of these ways into contact with the human body (such as bin liners).

We checked periodically that the experiments were performed correctly during treatment and control periods and took photographs to confirm that the treatment was properly implemented.

Table 2: Treatment and control phases.

\begin{tabular}{lcc} 
& Phase 1 & Phase 2 \\
& 30 May $-\mathbf{2 6}$ June & 27 June $-\mathbf{2 4}$ July \\
\hline Group 1 (2 stores) & Treatment & Control \\
Group 2 (2 stores) & Control & Treatment \\
\hline
\end{tabular}

\section{Research design and Methodology}

\subsection{Discrete-choice model}

The econometric specification that we will present in section 5 hinges on the Nevo (2010) theoretical benchmark. According to Nevo (2010) the indirect utility of consumer $i$ from consuming good $j$ in market $k$ is

$$
U_{i j t}=U\left(x_{j t}, \xi_{j t}, I_{i}-p_{j t}, \tau_{i} ; \theta\right)
$$

where $x_{j t}$ is a vector of observed good characteristics, $\xi_{j t}$ is a vector of unobserved (by the researchers) good characteristics (i.e., the positive value perception of the treated products for consumers with other-regarding preferences), $I_{i}-p_{j t}$ represents the income-price difference, $\tau_{i}$ are individual characteristics, and $\theta$ is a vector of parameters to be estimated. 
A simplified version of indirect utility writes

$$
u_{i j t}=\alpha_{i}\left(I_{i}-p_{j t}\right)+\beta_{i} x_{j t}+\xi_{j t}+\varepsilon_{i j t}
$$

where $\varepsilon_{i j t}$ is a stochastic term. The parameter $\alpha_{i}$ is the individual marginal utility from income and $\beta_{i}$ is a $K \times 1$ vector of individual specific taste coefficient. The vector $\xi_{j t}$ captures unobserved good characteristics, unquantifiable factors (including the focus of our experiment, that is, the environmental responsibility of the brand), systematic demand shocks, or unobserved promotional activity. The introduction of $\xi_{j t}$ not only helps in explaining the data, but also implies that, if firms observe $\xi_{j t}$ before making production plans, prices and other choice variables could be endogenous.

The individual taste parameters are modelled as

$$
\begin{aligned}
\alpha_{i} & =\alpha+\sum_{r=1}^{d} \pi_{1 r} D_{i r}+\sigma_{1} v_{i 1} \\
\beta_{i k} & =\beta_{k}+\sum_{r=1}^{d} \pi_{(k+1) r} D_{i r}+\sigma_{k+1} v_{i(k+1)} \text { for } k=1, \ldots, K
\end{aligned}
$$

where $D_{i}$ is a $d \times 1$ vector of observed socio-demographic variables, $v_{i}$ is a vector of $K+1$ unobserved individual characteristics, assumed to have a standard normal distribution $F_{v}, \Pi=$ $\left(\pi_{m n}\right)_{m=1, \ldots, K+1, n=1, \ldots, d}$ is a $(K+1) \times d$ matrix of parameters, and $\sigma=\left(\sigma_{1}, \ldots, \sigma_{K+1}\right)$ is a vector of parameters. The individual indirect utility from the outside option - that is from not purchasing any of the goods - is given by

$$
u_{i 0 t}=\alpha_{i} I_{i}+\varepsilon_{i 0 t}
$$

Since we are interested in the relative utilities, we remove the individual income term $I_{i}$. Then, by combining equations ( $\underline{1})$ and $(\underline{2})$ we obtain

$$
u_{i j t}=\delta_{j t}+\mu_{i j t}+\varepsilon_{i j t}
$$

where $\delta_{j t}=x_{j t} \beta-\alpha p_{j t}+\xi_{j t}$ is the mean utility across consumers and $\mu_{i j t}=-\left(\sum_{r=1}^{d} \pi_{1 r} D_{i r}+\right.$ $\left.\sigma_{1} v_{i 1}\right) p_{j t}+\sum_{k=1}^{K}\left(\sum_{r=1}^{d} \pi_{(k+1) r} D_{i r}+\sigma_{k+1} v_{i(k+1)}\right) x_{j t}^{k}$ is the interaction of consumer socio-demographics and good characteristics, which together with the random term $\varepsilon_{i j t}$ captures the variation around the mean utility $\delta_{j t}$.

The probability that a consumer of type $\left(D_{i}, v_{i}\right)$ chooses good $j$ is

$$
s_{i j t}=\int \mathbb{1}\left[u_{i j t} \geq u_{i k t} \forall l \mid x_{t}, \delta_{t}, p_{t}, D_{i}, v_{i} ; \theta\right] d F_{\varepsilon}(\varepsilon)
$$

where $\mathbb{1}[\cdot]$ is the indicator function.

Thus, market shares are given by

$$
s_{j t}=s_{j t}\left(x_{t}, \delta_{t}, p_{t} ; \theta\right)=\int s_{i j t} d F_{D}(D) F_{v}(v)
$$

If we assume $\Pi=0, \sigma=0$ (which imply $\beta_{i}=\beta$ and $\alpha_{i}=\alpha$ for all $i$ ), $\varepsilon_{i j t}$ are iid and follows a Gumbel distribution, then we can apply the multinomial logit model and the market shares are given by

$$
s_{j t}=\frac{\exp \left\{x_{j t} \beta-\alpha p_{j t}+\xi_{j t}\right\}}{1+\sum_{k=1}^{J} \exp \left\{x_{j t} \beta-\alpha p_{j t}+\xi_{j t}\right\}}
$$




\subsection{Hypothesis testing}

Our field experiment consists in testing the following four hypotheses separately for each of the three (Label, Label5, and Label10) treatments.

The first hypothesis is

$H_{01}^{T_{i}}=$ (insignificance of the $i$-th treatment for any of the VV products in the treated product class).

The null of $H_{01}^{T i}$ states that the $i$-th treatment has no effect on consumers' choices, that is, the treatment does not change any of the market shares of the $18 \mathrm{VV}$ products considered in the experiment. This should be the case in the presence of the following two conditions: i) purely self-regarding consumer preferences and ii) no concern for health related problems arising from the purchase of less environmentally sustainable products. Rejection of the null for some of the VV products once consumers' imperfect information on their environmentally sustainable characteristics is reduced by the shelf poster treatment would imply that provision of information on corporate environmental responsibility is a strategy that marketing experts and/or policymakers may successfully choose in order to affect product sales. Such rejection in turn implies that consumers perceive a nexus between environmental sustainability and their health or, if this is not the case, have other-regarding preferences (see the theoretical framework in the Appendix).

$H_{02}^{T_{i}}=$ (insignificance of the $i$-th treatment for the food VV products)

The null of $H_{02}^{T_{i}}$ states that the treatment does not affect in aggregate sales of VV food products, that is, the aggregate market share of the specific food VV products within their specific product classes becomes not significantly different when the treatment is introduced. The rejection of the null in direction of higher market shares with the treatment again implies that the information strategy works and can be successfully implemented for marketing or welfare purpose. Even in this case, rejection of the null may be further interpreted in two directions: i) consumers care about their health and believe that, by buying an environmentally sustainable food product, they may positively contribute to it; ii) consumers have in their utility function an argument that gives positive value to environmental sustainability per se. Under ii) we have a case for other-regarding preferences under the reasonable assumption that a single consumer choice of the green product does not produce per se a positive environmental externality on the same consumer large enough to compensate the loss of utility arising for the deviation from her $/$ his optimal pre-treatment choice (see the theoretical framework in the Appendix). Under case i) self-regarding preferences and, more specifically, care for one's own health are sufficient to explain what we observe.

$H_{03}^{T i}=$ (insignificance of the $i$-th treatment for the non-food VV products)

The third null hypothesis states that the treatment does not affect in aggregate sales of VV non-food products. Note here that rejection of the null in the direction of higher market shares of VV non-food products under the treatment (the shelf poster on environmental sustainability) is less likely to be be interpreted as arising from health concerns since non-food products are less likely to affect health. We remark however that not all non-food products may strictly be considered as not affecting personal health. With reference to our products, consumers may believe that non ecological dish detergents, lip protectors and surface cleaners may in some sense be related to products or chemical substances that are detrimental to health. We therefore identify a subset of VV non-food products that may be considered as more distant from personal health considerations (or for which the green characteristics are expected to be less likely to affect 
personal health). We think that bin liners are the product that is more distant from affecting personal health.

In order to disentangle the two interpretations for the rejection of the null under hypotheses one, two and three we therefore formulate hypothesis four as follows

$H_{04}^{T i}=$ (insignificance of the shelf poster treatment for the bin liner VV product)

the fourth null is a sharper test on the existence of other-regarding preferences since the product object of our test is the most distant from having consequences on consumers' health. More specifically in this respect, we consider a taxonomy of four types of products according to consumers' perception of their potential impact on health: i) food products; ii) non-food products that enter directly or indirectly into contact with the human body (i.e., lip protectors, dish detergents, shower products, napkins); iii) non-food products that produce emissions that can be inhaled (i.e., surface cleaners); iv) non-food products that do not have characteristics of products in ii) and iii) (i.e., bin liners). The null of $H_{04}^{T i}$ relates to the insignificant effect of the treatment on products in category iv).

\section{Descriptive and econometric analysis}

Table 3 shows the list of products that are labeled, divided by market class with their relative prices. Market classes are defined by Coop and they reflect the arrangement of the products in the shelves. This allows us to consider all the products within a selected market as substitutes. Table 4 shows descriptive statistics for the prices in each market. It also contains statistics regarding the difference between the price and the average market price. We notice that, on average, the price of VV products is lower than the average market price. This contradicts the common opinion that environmentally sustainable products cost more than their substitutes.

Table 3: List of $V V$ products selected for the treatment.

\begin{tabular}{llc}
\hline Product class & Product & Price (24-Mar-2016) \\
\hline Teas & Fruits Tea, 20p & 1.57 \\
Pasta & Spaghetti, 500g & 0.75 \\
Pasta & Fusilli, 500g & 0.75 \\
Pasta & Penne, 500g & 0.75 \\
Pasta & Whole Wheat Spaghetti, 500g & 0.75 \\
Pasta & Whole Wheat Fusilli, 500g & 0.75 \\
Pasta & Whole Wheat Penne, 500g & 0.75 \\
Pasta & Whole Wheat Ditali, 500g & 0.75 \\
Bread and substitutes & Whole Wheat Crackers, 150g & 0.66 \\
Tomato preserves & Tomato Pulp, 690g & 0.89 \\
Dish detergents & Washing-up Liquid, 1l & 1.05 \\
Big surface cleaners & Floor Cleaner 'Camellia', 1l & 1.35 \\
Small surface cleaners & Glass Cleaner, 750ml & 1.67 \\
Bin Liner & Bin Liner, 15l 15p & 1.95 \\
Tablecloths and napkins & 2-ply Napkins, 33×33×50 & 0.63 \\
Disposable table covers & Plastic Cups 200cc no. 25 & 1.01 \\
Bathroom products & Shower Gel, 250ml & 2.10 \\
Toilet paper & Toilet Paper, 4 Rolls & 1.90 \\
Lip protectors & Lip Balm & 1.86 \\
Handkerchief & 4-Ply Paper Handkerchief, 10×9 & 0.77 \\
Fruit Juices & Blood Orange Juice, 750ml & 1.70 \\
White kidney beans & White kidney beans, 500g & 1.98 \\
\hline
\end{tabular}


Table 4: Descriptive statistics of the products in the selected product classes.

\begin{tabular}{|c|c|c|c|c|c|}
\hline Variable & Obs. & Mean & Std. Dev. & Min & Max \\
\hline \multicolumn{6}{|c|}{ Average prices } \\
\hline Pasta & 10,228 & 1.20 & 0.755 & 0.38 & 5.90 \\
\hline Bread and substitutes & 2,200 & 1.77 & 0.790 & 0.55 & 4.99 \\
\hline Tomato preserves & 3,682 & 1.43 & 0.703 & 0.35 & 9.84 \\
\hline Dish detergents & 3,237 & 3.20 & 2.258 & 0.47 & 17.80 \\
\hline Big surface cleaners & 3,012 & 2.23 & 1.323 & 0.29 & 6.99 \\
\hline Small surface cleaners & 4,857 & 2.39 & 1.143 & 0.59 & 9.8 \\
\hline Bin liners & 923 & 1.67 & 1.166 & 0.65 & 7.80 \\
\hline Tablecloths and napkins & 938 & 1.76 & 1.280 & 0.39 & 6.99 \\
\hline Disposable table covers & 1,504 & 1.93 & 1.235 & 0.49 & 5.09 \\
\hline Bathroom products & 10,641 & 2.32 & 1.218 & 0.48 & 11.9 \\
\hline Toilet paper & 865 & 2.95 & 1.699 & 0.99 & 9.90 \\
\hline Lip protectors & 675 & 2.23 & 1.195 & 0.74 & 4.73 \\
\hline Handkerchief & 856 & 1.75 & 1.257 & 0.47 & 7.98 \\
\hline Fruit juices & 457 & 2.27 & 0.804 & 1.59 & 3.69 \\
\hline White kidney beans & 5,021 & 2.25 & 1.016 & 0.90 & 8.40 \\
\hline \multicolumn{6}{|c|}{ Average $V V$ prices } \\
\hline Pasta & 523 & 1.27 & 0.683 & 0.75 & 2.18 \\
\hline Bread and substitutes & 144 & 1.30 & 0.649 & 0.66 & 2.19 \\
\hline Tomato preserves & 192 & 0.79 & 0.081 & 0.69 & 0.89 \\
\hline Dish detergents & 185 & 1.26 & 0.809 & 0.52 & 2.59 \\
\hline Big surface cleaners & 55 & 1.26 & 0.243 & 0.55 & 1.35 \\
\hline Small surface cleaners & 95 & 1.49 & 0.176 & 1.32 & 1.67 \\
\hline Bin liners & 132 & 1.30 & 0.430 & 0.99 & 1.95 \\
\hline Tablecloths and napkins & 48 & 0.63 & 0 & 0.63 & 0.63 \\
\hline Disposable table covers & 130 & 2.18 & 0.820 & 1.09 & 2.79 \\
\hline Bathroom products & 96 & 1.98 & 0.126 & 1.85 & 2.10 \\
\hline Toilet paper & 48 & 1.90 & 0 & 1.90 & 1.90 \\
\hline Lip protectors & 47 & 1.86 & 0 & 1.86 & 1.86 \\
\hline Handkerchief & 48 & 0.79 & 0 & 0.79 & 0.79 \\
\hline Fruit juices & 48 & 1.70 & 0 & 1.70 & 1.70 \\
\hline White kidney beans & 523 & 1.90 & 0.225 & 1.35 & 2.40 \\
\hline
\end{tabular}

Table 5 presents total treatment and control sales in each of the selected supermarkets, while Table $\underline{\overline{6}}$ does it for each of the treated product class. Under all of the three treatment conditions jointly considered overall sales for our selected markets increase by 1.7 percent, even if this increase is not homogeneous across the different markets. Total sales of VV products also grow by 0.9 percent, and by 6 percent under the label plus 5 percent price increase treatment. However, under the label plus 10 percent price increase treatment, sales decrease by 2.3 percent. These weak aggregate findings conceal strong heterogeneity in treatment effects across the different VV products. The econometric analysis that follows will help to shed light on this seemingly insignificant effect of the treatment when viewed at aggregate level with descriptive findings.

Table 5: Total store sales, by treatment.

\begin{tabular}{lrrrr}
\hline & \multicolumn{2}{c}{ Total Sales $(€)$} & \multicolumn{2}{c}{ Sales of selected markets $(€)$} \\
Store & Control & Treatment & Control & Treatment \\
\hline Gavinana & $6,243,215$ & $5,938,517$ & 76,184 & 70,702 \\
Empoli & $6,274,692$ & $6,213,352$ & 74,480 & 73,491 \\
Pontedera & $4,152,686$ & $4,116,991$ & 55,595 & 57,346 \\
Prato & $7,123,529$ & $7,184,454$ & 87,479 & 88,072 \\
Figline & $4,953,176$ & $5,379,769$ & 65,559 & 67,201
\end{tabular}




\begin{tabular}{lrrrr} 
Ponte a Greve & $6,136,128$ & $6,768,738$ & 73,079 & 79,104 \\
Pontassieve & $3,779,418$ & $3,754,279$ & 54,029 & 52,048 \\
Poggibonsi & $4,929,677$ & $4,839,383$ & 59,828 & 60,831 \\
Borgo San Lorenzo & $3,646,086$ & $3,570,964$ & 52,713 & 56,234 \\
Pistoia & $4,261,048$ & $4,144,520$ & 53,502 & 51,369 \\
Montevarchi & $5,766,883$ & $5,636,025$ & 72,628 & 72,352 \\
Sesto Fiorentino & $5,724,176$ & $6,007,893$ & 68,378 & 70,850 \\
Total & $6.30 \mathrm{e}+07$ & $6.36 \mathrm{e}+07$ & 793,454 & 799,599 \\
\hline
\end{tabular}

Table 6: Market sales, by market-treatment.

\begin{tabular}{|c|c|c|}
\hline \multirow[b]{2}{*}{ Store } & \multicolumn{2}{|c|}{ Total Sales (by market, $€$ ) } \\
\hline & Control & Treatment \\
\hline Pasta & $79,627.43$ & $81,333.13$ \\
\hline Bread and substitutes & $65,132.94$ & $62,862.79$ \\
\hline Tomato preserves & $41,635.62$ & $41,393.00$ \\
\hline Dish detergents & $51,315.75$ & $49,950.20$ \\
\hline Surface cleaners & $69,143.00$ & $66,370.17$ \\
\hline House cleaning optional & $66,262.56$ & $66,827.76$ \\
\hline Bin liners & $15,866.63$ & $15,690.69$ \\
\hline Tablecloths and napkins & $15,645.79$ & $15,882.90$ \\
\hline Disposable table covers & $34,098.63$ & $34,850.14$ \\
\hline Bathroom products & $63,130.71$ & $68,577.24$ \\
\hline Toilet paper & $56,161.28$ & $57,496.33$ \\
\hline Lip protectors & $2,232.98$ & $2,359.42$ \\
\hline Tissues & $8,720.25$ & $9,006.13$ \\
\hline Fruit juices & $4,313.36$ & $4,142.09$ \\
\hline White kidney beans & $1,919.73$ & $2,166.96$ \\
\hline
\end{tabular}

\section{Econometric analysis}

In order to measure the impact of the treatment gross effect, we perform a reduced-form econometric analysis. Using a simple specification that follows in part Hainmueller et al. (2014) we regress the log of the weekly VV sales on the treatment indicators controlling for week/store fixed effects and prices. We split the 18 selected product classes into two groups: food products and non-food products. In particular, we regress the following specification

$$
\log \left(s_{i, w}\right)=\alpha+\beta_{0} \text { Treatment }_{w}+\sum_{h} \alpha_{1, h} \text { Week }_{h}+\sum_{k} \alpha_{2, k} \text { Store }_{h}+\alpha_{3} \text { Price }_{i, w}+\epsilon_{i, w}
$$

where $\log \left(s_{i, w}\right)$ is the $\log$ of the sales of the VV product $i$ in week $w$; Treatment $w_{w}$ is a $(0 / 1)$ dummy during the treatment phase (total and separated for each treatment); Week ${ }_{h}$ and Store ${ }_{k}$ capture the week and store fixed effects. We also control for the price of product $i$ in week $w$, Price $_{i, w}$. All the standard errors are clustered at the store level to take into account potential within-store correlation over time.

Table 7 shows that the overall effect of the treatment is positive and statistically significant for the food products. In terms of economic significance the treatment generates a two percent growth in sales. When we decompose the effect into the three different (Label, Label5, and Label10) treatments we find an aggregate food effect concentrated on the 10 percent price increase treatment with a 4.3 percent growth in log sales.

Table 7: Reduced-form analysis. 


\begin{tabular}{lcccc} 
Variables & $\begin{array}{c}\text { Food } \\
\text { Log(sales) }\end{array}$ & $\begin{array}{c}\text { Food } \\
\text { Log(sales })\end{array}$ & $\begin{array}{c}\text { NonFood1 } \\
\text { Log(sales) }\end{array}$ & $\begin{array}{c}\text { NonFood2 } \\
\text { Log(sales })\end{array}$ \\
\hline VV (total) & $\begin{array}{c}0.0244^{* * *} \\
(0.00654)\end{array}$ & & $-0.0229^{*}$ & \\
VV Label & & 0.0197 & & $-0.0610^{* *}$ \\
& & $(0.0116)$ & & $(0.0222)$ \\
VV Label 5 & & 0.0103 & & -0.00712 \\
& & $(0.00585)$ & & $(0.0133)$ \\
VV Label10 & & $0.0433^{* * *}$ & & -0.00138 \\
& & $(0.00759)$ & & $(0.0114)$ \\
Price & $-0.283^{* * *}$ & $-0.283^{* * *}$ & $-0.048^{* * *}$ & $-0.048^{* * *}$ \\
& $(0.00558)$ & $(0 . .00557)$ & $(0.00738)$ & $(0.00736)$ \\
Store FE & Yes & Yes & Yes & Yes \\
Week FE & Yes & Yes & Yes & Yes \\
Observations & 3,212 & 3,212 & 3,497 & 3,497 \\
R-squared & 0.047 & 0.047 & 0.011 & 0.012 \\
\hline
\end{tabular}

Robust standard errors in parentheses.

$* * * \mathrm{p}<0.01,{ }^{* *} \mathrm{p}<0.05,{ }^{*} \mathrm{p}<0.1$

These summary aggregate econometric findings need to be decomposed in order to understand which product classes drive them. In order to test whether our treatments are significant net of the impact of confounding factors, we estimate the following specification

$$
\begin{aligned}
\delta_{i j t}= & \beta_{0} \text { TreatVV }+\sum_{b} \beta_{1, b} \text { TreatBrand }_{b} \\
& +\sum_{h} \alpha_{1, h} \text { Week }_{h}+\sum_{k} \alpha_{2, k} \text { BrandStore }_{k}+\alpha_{3} \text { Price }_{i j t}+\epsilon_{i j t}
\end{aligned}
$$

where $\delta_{i j t}:=\log \left(s_{i j t}\right)-\log \left(s_{00 t}\right)$ are the mean utility levels as a function of the observed market shares for good $i$ belonging to brand $j$ at week $t$; Treat $\mathrm{V}_{b}$ is a $(0 / 1)$ dummy for the $\mathrm{VV}$ brand during the treatment phase; TreatBrand ${ }_{b}$ is a $(0 / 1)$ dummy for the brands within the same product class of the VV treated products during the treatment phase; Week ${ }_{h}$ and BrandStore $_{k}$ are $(0 / 1)$ dummy variables capturing the week and the brand/store fixed effects respectively; Price $_{i j t}$ represents the unit price level of good $i$ belonging to brand $j$ at week $t$. We cluster standard errors at the store level.

We differ from the standard discrete choice model (Nevo, 2010) by using the market share of the brands rather than the products, as we are interested in investigating the effect of the treatment on the VV brand. We also control for the price level that should matter especially under the (label plus) 5 and 10 percent increase experiment where the initial price level may be important while the same should not matter in label experiments.

Table 8: Label and Price Experiment effect on VV goods, by market.

\begin{tabular}{lccccc}
\hline \multirow{2}{*}{ Market } & VV & \multicolumn{2}{c}{ VV } & Elasticity \\
& Total & Label & Price $5 \%$ & Price $10 \%$ & \\
\hline Teas & 0.0620 & -0.0489 & -0.00992 & $0.249^{* *}$ & 0.017 \\
& $(0.0741)$ & $(0.150)$ & $(0.0721)$ & $(0.0843)$ & $(0.0102)$ \\
Obs. & 9,953 & & 9,953 & &
\end{tabular}




\begin{tabular}{|c|c|c|c|c|c|}
\hline$R^{2}$ & 0.288 & & 0.290 & & \\
\hline Long-cut wheat pasta & $\begin{array}{r}-0.00510 \\
(0.0585)\end{array}$ & $\begin{array}{c}-0.0796 \\
(0.0998)\end{array}$ & $\begin{array}{c}0.0546 \\
(0.128)\end{array}$ & $\begin{array}{c}0.00970 \\
(0.0441)\end{array}$ & $\begin{array}{c}0.076^{* * *} \\
(0.006)\end{array}$ \\
\hline Obs. & 5,066 & & 5,066 & & \\
\hline$R^{2}$ & 0.600 & & 0.602 & & \\
\hline Short-cut wheat pasta & $\begin{array}{l}-0.0627 \\
(0.0625)\end{array}$ & $\begin{array}{c}-0.176 \\
(0.112)\end{array}$ & $\begin{array}{c}0.0667 \\
(0.0993)\end{array}$ & $\begin{array}{c}-0.0792 \\
(0.0678)\end{array}$ & $\begin{array}{c}0.059^{* * *} \\
(0.0072)\end{array}$ \\
\hline Obs. & 10,468 & & 10,468 & & \\
\hline$R^{2}$ & 0.523 & & 0.524 & & \\
\hline Whole-wheat pasta & $\begin{array}{c}-0.00300 \\
(0.0335)\end{array}$ & $\begin{array}{c}0.105^{* * *} \\
(0.0332)\end{array}$ & $\begin{array}{l}-0.0808 \\
(0.0579)\end{array}$ & $\begin{array}{c}-0.0374 \\
(0.0545)\end{array}$ & $\begin{array}{c}-0.988^{* *} \\
(0.4291)\end{array}$ \\
\hline Obs. & 1,439 & & 1,439 & & \\
\hline$R^{2}$ & 0.743 & & 0.746 & & \\
\hline Bread and substitutes & $\begin{array}{c}0.0443^{*} \\
(0.0206)\end{array}$ & $\begin{array}{c}0.00282 \\
(0.0311)\end{array}$ & $\begin{array}{c}0.0844^{* *} \\
(0.0358)\end{array}$ & $\begin{array}{c}0.0457 \\
(0.0255)\end{array}$ & $\begin{array}{c}0.053^{*} \\
(0.0283)\end{array}$ \\
\hline Obs. & 4,405 & & 4,405 & & \\
\hline$R^{2}$ & 0.673 & & 0.674 & & \\
\hline Tomato preserves & $\begin{array}{c}0.0319 \\
(0.0306)\end{array}$ & $\begin{array}{c}0.0764^{* * *} \\
(0.0209)\end{array}$ & $\begin{array}{c}-0.0130 \\
(0.0766)\end{array}$ & $\begin{array}{c}0.0322 \\
(0.0328)\end{array}$ & $\begin{array}{c}-0.055^{* * *} \\
(0.0156)\end{array}$ \\
\hline Obs. & 7,332 & & 7,332 & & \\
\hline$R^{2}$ & 0.482 & & 0.483 & & \\
\hline Dish detergents & $\begin{array}{c}-0.0955 \\
(0.111)\end{array}$ & $\begin{array}{c}-0.291 \\
(0.303)\end{array}$ & $\begin{array}{l}-0.0328 \\
(0.0555)\end{array}$ & $\begin{array}{c}0.0325 \\
(0.0707)\end{array}$ & $\begin{array}{c}0.018^{*} \\
(0.0096)\end{array}$ \\
\hline Obs. & 6,401 & & 6,401 & & \\
\hline$R^{2}$ & 0.372 & & 0.376 & & \\
\hline Big surface cleaners & $\begin{array}{c}0.265^{*} \\
(0.122)\end{array}$ & $\begin{array}{c}0.331 \\
(0.268)\end{array}$ & $\begin{array}{c}0.419^{* * *} \\
(0.0406)\end{array}$ & $\begin{array}{l}0.0365 \\
(0.108)\end{array}$ & $\begin{array}{c}0.006 \\
(0.0124)\end{array}$ \\
\hline Obs. & 5,941 & & 5,941 & & \\
\hline$R^{2}$ & 0.493 & & 0.495 & & \\
\hline Small surface cleaners & $\begin{array}{c}0.0472 \\
(0.0659)\end{array}$ & $\begin{array}{c}0.106 \\
(0.125)\end{array}$ & $\begin{array}{c}0.0612 \\
(0.0957)\end{array}$ & $\begin{array}{c}-0.0203 \\
(0.116)\end{array}$ & $\begin{array}{c}0.047^{* * *} \\
(0.0076)\end{array}$ \\
\hline Obs. & 9,624 & & 9,624 & & \\
\hline$R^{2}$ & 0.506 & & 0.508 & & \\
\hline Bin liner & $\begin{array}{c}-0.0154 \\
(0.0374)\end{array}$ & $\begin{array}{c}0.0640^{* *} \\
(0.0224)\end{array}$ & $\begin{array}{c}-0.105 \\
(0.100)\end{array}$ & $\begin{array}{c}-0.0118 \\
(0.0159)\end{array}$ & $\begin{array}{c}0.0004 \\
(0.0004)\end{array}$ \\
\hline Obs. & 1,837 & & 1,837 & & \\
\hline$R^{2}$ & 0.434 & & 0.434 & & \\
\hline Tablecloths and napkins & $\begin{array}{c}0.0831^{* *} \\
(0.0284)\end{array}$ & $\begin{array}{c}0.0561 \\
(0.0592)\end{array}$ & $\begin{array}{c}0.119^{*} \\
(0.0551)\end{array}$ & $\begin{array}{c}0.0742^{* *} \\
(0.0259)\end{array}$ & $\begin{array}{c}0.327^{* * *} \\
(0.0587)\end{array}$ \\
\hline Obs. & 1,859 & & 1,859 & & \\
\hline$R^{2}$ & 0.699 & & 0.700 & & \\
\hline Disposable table covers & $\begin{array}{c}0.0336 \\
(0.0980)\end{array}$ & $\begin{array}{l}0.0325 \\
(0.175)\end{array}$ & $\begin{array}{r}-0.0212 \\
(0.198)\end{array}$ & $\begin{array}{l}0.0921 \\
(0.129)\end{array}$ & $\begin{array}{c}-0.171^{* * *} \\
(0.0081)\end{array}$ \\
\hline Obs. & 2,993 & & 2,993 & & \\
\hline$R^{2}$ & 0.420 & & 0.420 & & \\
\hline Bathroom products & $\begin{array}{c}0.134^{*} \\
(0.0678)\end{array}$ & $\begin{array}{c}0.111 \\
(0.0822)\end{array}$ & $\begin{array}{c}0.0198 \\
(0.0547)\end{array}$ & $\begin{array}{c}0.270 \\
(0.151)\end{array}$ & $\begin{array}{l}-0.012^{*} \\
(0.0055)\end{array}$ \\
\hline $\begin{array}{l}\text { Obs. } \\
R^{2}\end{array}$ & $\begin{array}{c}21,077 \\
0.243\end{array}$ & & $\begin{array}{c}21,077 \\
0.244\end{array}$ & & \\
\hline Toilet paper & $\begin{array}{c}-0.00453 \\
(0.0700)\end{array}$ & $\begin{array}{c}0.0481 \\
(0.0782)\end{array}$ & $\begin{array}{c}-0.0483 \\
(0.0877)\end{array}$ & $\begin{array}{c}-0.0123 \\
(0.174)\end{array}$ & $\begin{array}{c}0.216^{* * *} \\
(0.0329)\end{array}$ \\
\hline Obs. & 1,729 & & 1,729 & & \\
\hline$R^{2}$ & 0.632 & & 0.635 & & \\
\hline Lip protectors & $\begin{array}{l}0.0911 \\
(0.119)\end{array}$ & $\begin{array}{c}-0.0545 \\
(0.310)\end{array}$ & $\begin{array}{c}0.195 \\
(0.143)\end{array}$ & $\begin{array}{c}0.137^{* * *} \\
(0.0330)\end{array}$ & $\begin{array}{c}0.239^{* * *} \\
(0.0264)\end{array}$ \\
\hline Obs. & 1,349 & & 1,349 & & \\
\hline$R^{2}$ & 0.354 & & 0.358 & & \\
\hline Tissues & $\begin{array}{c}0.0112 \\
(0.0313)\end{array}$ & $\begin{array}{c}0.0472 \\
(0.0604)\end{array}$ & $\begin{array}{l}-0.0302 \\
(0.0522)\end{array}$ & $\begin{array}{c}0.0165 \\
(0.0437)\end{array}$ & $\begin{array}{l}-0.372^{*} \\
(0.0171)\end{array}$ \\
\hline Obs. & 1,723 & & 1,723 & & \\
\hline$R^{2}$ & 0.740 & & 0.739 & & \\
\hline Fruit juices & $\begin{array}{l}0.182^{* *} \\
(0.0808)\end{array}$ & $\begin{array}{c}0.138 \\
(0.113)\end{array}$ & $\begin{array}{c}0.143 \\
(0.103)\end{array}$ & $\begin{array}{c}0.298^{* *} \\
(0.119)\end{array}$ & $\begin{array}{c}0.594 \\
(0.4390)\end{array}$ \\
\hline
\end{tabular}




\begin{tabular}{lcccc|c} 
Obs. & 896 & & 896 \\
$R^{2}$ & 0.541 & & 0.549 & \\
White kidney beans & $0.128^{*}$ & 0.0560 & $0.255^{*}$ & 0.0703 & $0.100^{* * *}$ \\
& $(0.0627)$ & $(0.0992)$ & $(0.116)$ & $(0.0717)$ & $(0.0069)$ \\
Obs. & 9,967 & & 9,967 & & \\
$R^{2}$ & 0.123 & & 0.125 & \\
\hline All estimates include week and brand/store fixed effects as well as price control. \\
Robust standard errors in parentheses and clustered at store level. \\
$* * * \mathrm{p}<0.01,{ }^{*} \mathrm{p}<0.05,{ }^{*} \mathrm{p}<0.1$
\end{tabular}

As explained in the introduction, the original characteristic of our field experiment consists of the simultaneous application of the treatment on a large set of products and not on one product only as in Hainmueller, Hiscox and Sequeira (2014). This novel feature allows us to formulate new research questions such as on which of the treated products the treatment has significant effects.

The issue at stake in this research question is that it is unrealistic to expect that the treatment raises expenditure on all the treated products given that this could produce a too strong impact on the aggregate increase in expenditure. The expected selection of effects on the treated products should produce redistributive effects implying a hierarchy of preferences among them. Hence the experiment allows us to understand what are the products on which there is more range for improvement with green nudging and which of their characteristics are more likely to determine such improvement (our null hypotheses $2-4$ relate to this last point).

Econometric findings presented in Table $\underline{8}$ show that the treatment is significant for 11 out of 18 products (even though weakly so in two cases), thereby rejecting the null $\left(H_{01}\right)$ described in section 3.2. The effect is unevenly distributed among the three (Label, Label5, and Label10) treatments. In terms of economic significance, the strongest effect is the 47 percent increase on small surface cleaners, with many other significant effects being above the 10 percent increase in magnitude. Another characteristic of our findings is that the significance of the treatment seems to be stronger on food than on non-food products. More specifically, the treatment is significant on six out of eight food products. The two cases of non significance concern two pasta subclasses, while the third pasta subclass with product characteristics that are closer to the environmental sustainability perception (i.e., whole wheat pasta) registers a significant effect.

The pattern of economic significance of the treatment effects is not negligible, especially if we consider that at least three factors may contribute to reduce the impact of our treatment. First, our experiment occurs at the end of a long recession period in Italy (OECD, 2015) originated by the global financial crisis that led to a reduction of 12 percent of Italian household income. It is therefore reasonable to assume that the willingness to pay for environmental sustainability may have been weakened by the prolonged crisis spell in this historical period. Second, coop supermarkets are attended by consumers who are more sensitive to sustainability than average, since most of them are also shareholders of the Coop chain and the Coop movement has a long tradition of sensitivity to social and environmental problems. We therefore expect the shares of the VV products to be already at high levels, and room for further improvement is thus limited. Third, the photo of our experiment setting (see Figures 2) shows that the shelf poster has a message printed in a standard low size font that may not be easily read by consumers with poor eyesight. In this sense our goal was to test whether even a weak green nudging signal could produce significant effects on consumption shares of the treated products.

A final important finding of our experiment is related to the hypothesis of the existence of otherregarding preferences. As explained above we need to disentangle to this purpose the environment effect from the health effect. The self-regarding health effect is presumed to be stronger on food 
products that enter consumers' body, weaker but still present on products that come into contact with consumers' body (i.e., lip protectors) and even weaker on products that do not enter into contact with consumers' body but that emit substances that can be inhaled (i.e., surface cleaners and detergents). The only product that has none of these three characteristics is bin liners. Our findings show that our treatment is significant on that product and therefore provide evidence in favour of rejection of $\left(H_{04}\right)$, that is, the null of absence of other-regarding preferences.

\section{Conclusions}

We perform a green nudging natural experiment with crossover design by using as a treatment a poster on supermarket shelves explaining the importance of environmental responsibility in proximity of 18 green (VV) products. Our findings document a significant and economically remarkable effect on treated products' market shares in many of the relevant product market subclasses. Part of the effect is determined by the price inelasticity of consumers in the poster plus price increase (Label5, Label10) treatments as shown by our estimated elasticities. Evidence of the significance of the treatment effect also on non-food products that presumably have limited effects on personal health, and, more so, evidence of significance on bin liners where health effects are irrelevant, suggests that the significant reaction to the treatment effect is partially due to the presence of non-purely self-regarding preferences.

Our experiment shows that emphasis on the environmentally responsible features of products placed in strategic places is a low cost, high impact policy that may significantly shift consumers toward green purchases. The cost-effectiveness of such policies should be compared with those based on more traditional incentive schemes. In a sense, the problem with environmental sustainability is that corporate profit functions do not internalise the negative environmental externalities of firm choices along the supply chain (notably in terms of emissions and waste management). The provision of information to final consumers on their level of environmental responsibility at selling places may be in this respect crucial to internalise the negative social costs of such externalities helping to bridge the gap between private and social optimum.

Our findings have several implications in terms of policy and further research in the field. Our experiment documents significant effects on product sales of a small shelf poster experiment. One should ask what the aggregate effects could be of the provision of such information on large scale, and whether this could contribute to modify costs and rewards of environmentally sustainable choices at corporate level. Future research could also seek to estimate the effect of information providers such as TripAdvisor in the specific field of social and environmental responsibility as a stimulus for the production and the diffusion of information in this specific domain for the general public.

\section{References}

[1] Andreoni, J. (1989), "Giving with impure altruism: applications to charity and ricardian equivalence", Journal of Political Economy, University of Chicago Press, 97(6), 1447-58.

[2] Andreoni, J. (1990), "Impure altruism and donations to public goods: a theory of warm-glow giving?", Economic Journal, 100(401), 464-77.

[3] Becchetti, L. and Salustri, F. (2015), The vote with the wallet as a multiplayer prisoner's dilemma, AICCON Working Papers, 141. 
[4] Bolton, G., and Ockenfels, A. (2000), "ERC: A theory of equity, reciprocity, and competition", The American Economic Review, 90(1), 166-193.

[5] Charness, G. and Rabin, M. (2002), "Understanding social preferences with simple tests", The Quarterly Journal of Economics, 117(3), 817-869.

[6] Euromonitor International, Grocery Retailers in Italy, 2016, Country Report, 47 pages.

[7] Fehr, E. and Schmidt, K.M. (1999), "A theory of fairness, competition and cooperation", The Quarterly Journal of Economics, 114, 817-868.

[8] Goldstein, N., Cialdini, R., Griskevicius, V., and John Deighton served as editor and Mary Frances Luce served as associate editor for this article (2008), "A room with a viewpoint: Using social norms to motivate environmental conservation in hotels", Journal of Consumer Research, 35(3), 472-482.

[9] Goldstein, N.J. and Cialdini, R.B. (2009), Normative influences on consumption and conservation behaviors' In M. Wänke (Ed.), "Social psychology of consumer behavior", 273-296, New York: Psychology Press.

[10] Griskevicius,V., Cialdini, R.B., and Goldstein, N.J. (2008), "Social norms: An underestimated and underemployed lever for managing climate change", International Journal for Sustainability Communication, 3, 5-13.

[11] Hainmueller, J., Hiscox, M.J. and Sequeira, S. (2015), "Consumer demand for fair trade: Evidence from a multistore field experiment", The Review of Economics and Statistics, $97(2), 242-256$.

[12] Hiscox, M.J., Broukhim M. and Litwin C. (2011), Consumer demand for fair trade: New evidence from a field experiment using eBay auctions of fresh roasted coffee. Available at: http://dx.doi.org/10.2139/ssrn.1811783.

[13] Hudson, D., Gallardo, R.L. and Hanson, T.R. (2012) "A comparison of choice experiments and actual grocery store behavior: An empirical application to seafood products", Journal of Agricultural and Applied Economics, 44(1), 49 ?62.

[14] Jones, B. and Kenward, M.G. (2003), Design and analysis of cross-over trials, Second Edition (Monographs on Statistics and Applied Probability). New York: Chapman \& Hall

[15] Mansky, C.F. (1977), "The structure of random utility models", Theory and Decision, 8(3), $229-254$.

[16] McFadden, D. (1981), Econometric Models of Probabilistic Choice, in C.F. Manski and D. McFadden (eds.), "Structural analysis od discrete data with econometric applications", 198272, MIT Press: Cambridge, MA.

[17] McFadden, D. (1984), Econometric analysis of qualitative response models, ch. 24, 1395-1457 in Grilichest, Z. and Intriligator, M. D. eds., "Handbook of Econometrics", 2, Elsevier.

[18] Murray, K.B., Di Muro, F., Finn, A. and Popkowski Leszczyc, P. (2010), "The effect of weather on consumer spending", Journal of Retailing and Consumer Services, 17, 512-520.

[19] Nevo, A. (2010), "Empirical models of consumer behavior", Annual Review of Economics, $3,51-75$.

[20] OECD - Better Life Initiative Country Note (2015), How's life in Italy. Available at https: //www.oecd.org/statistics/Better\%20Life\%20Initiative\%20country\%20note\%20Italy.pdf. 
[21] Parker, P.M. and Tavassoli, N.T. (2000), "Homeostasis and consumer behavior across cultures", International Journal of Research in Marketing, 17, 33-53.

[22] Parsons, A.G. (2001), "The association between daily weather and daily shopping patterns", Australasian Marketing Journal, 9(2), 78-84.

[23] Rabin, M. (1993), "Incorporating fairness into Game theory and Economics", American Economic Review, 83(5), 1281-1302.

[24] Schubert, C. (2016), Green nudges: Do they work? Are they ethical?, Joint Discussion Paper Series in Economics, University of Kassel.

[25] Steele, A.T. (1951), "Weather's effect on the sales of a department store", Journal of Marketing, 15, 436-443.

[26] Thaler, R.H. and Sunstein, C.R. (2003), "Libertarian paternalism", American Economic Review, 93(2): 175-179. 
Figure 1: The labels during the treatment conditions in the Label (a) and the Label5 and Label10 (b) experiment.

(a)

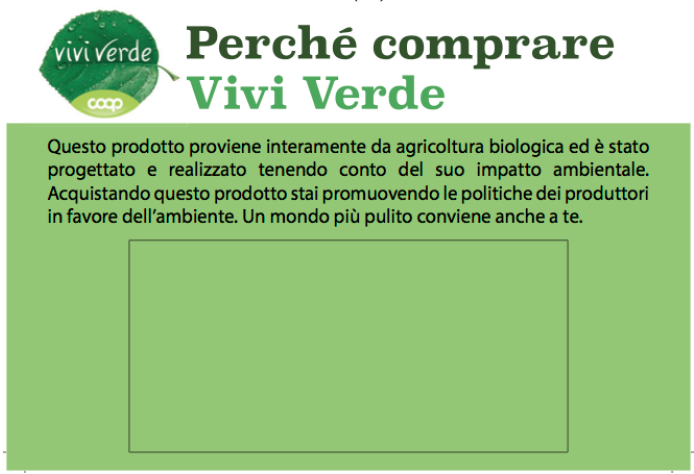

(b)

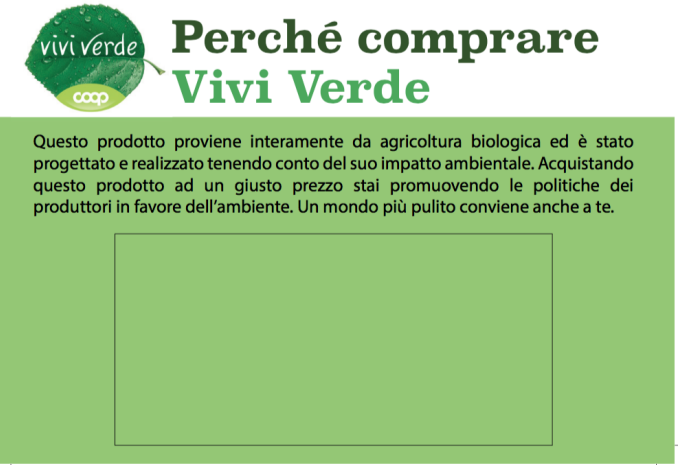

Figure 2: The labels on the shelves during the treatment phase.

(a)

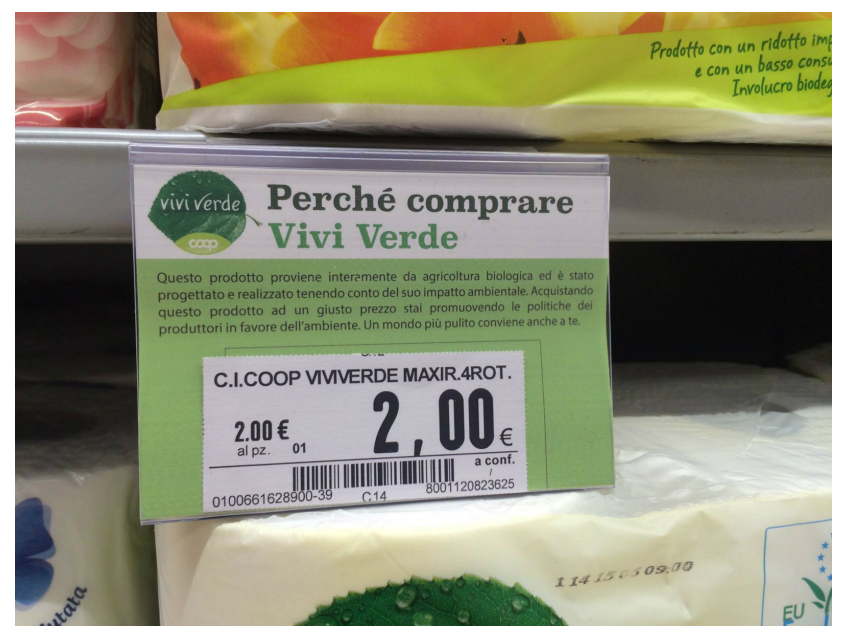

(b)

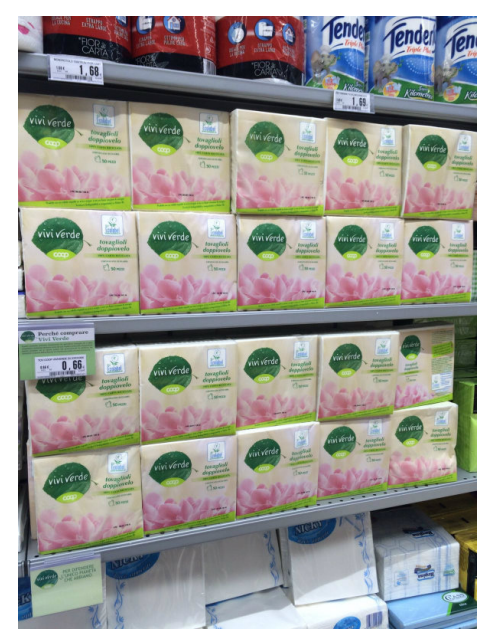

\section{The base model and the imperfect information versions}

In presence of a perception that an environmental friendly product has positive effect on one's own health, the positive impact of the shelf-treatment is trivially explained by self-regarding preferences. However, consider the case of products where consumer's perception of the link with health is absent.

Following Becchetti and Salustri (2015)'s vote with the wallet model, the utility function for each $j$-th consumer choosing the strategy $S^{j}$ may be written as

$$
U_{j}\left(S^{j}, k\right)= \begin{cases}\frac{k+1}{n} b+a-c & \text { if } S^{j}=R \\ \frac{k}{n} b & \text { if } S^{j}=C\end{cases}
$$

where $R$ indicates the strategy of buying responsibly (i.e., changing choices after having information from the campaign poster), $C$ the strategy of buying conventionally (i.e., not changing choices after having information from the campaign poster), and $k$ represents the number of responsible co-buyers. The model, conveniently and without lack of generality, assumes that the global common good effect is multiplicative on the share of consumers making the responsible choice. 
Since we are in large consumer markets, we conveniently assume that $n$ players are playing this game, with $n$ being very large and only a small subset of $n$ being represented by consumers buying in the supermarket where the poster is exposed. The area of the prisoner's dilemma for the individual consumer is defined by the following inequality

$$
\frac{1}{n} b+a<c<a+b
$$

and it is optimal to choose the responsible product only if

$$
c<\frac{1}{n} b+a
$$

The framework of our experiment is that of mass consumer markets where $n$ is very large. This implies that the first part of the LHS of the inequality gets close to zero. As a consequence, the consumer chooses the responsible product only if she has nonzero other-regarding preferences, even when the cost differential between the responsible and the conventional product (i.e., $c$ ) is small or, in formal terms, with $c>0$ and $\lim _{b \rightarrow \infty} \frac{1}{n} b=0$ inequality (5) holds if and only if $a>0$. It is trivial to check that, with perfect information on product characteristics, the area of the Prisoner's dilemma and the cooperation condition do not change with our base label (with no price increase) experiment. Hence the treatment should not produce any significant effect. Consider however now the following modified version of the model where consumers are imperfectly informed about corporate environmental responsibility and therefore the otherregarding argument entering the value of the cooperating choice is made by $a+e$, where $a$ is the deterministic component of the base model and $e$ is a normally distributed random variable with zero mean and variance $\sigma^{2}$ capturing uncertainty on the responsible characteristics of the product. Assume as well that risk averse consumers have a standard utility function with coefficient of risk aversion $\gamma$.

The Prisoner's dilemma condition therefore becomes

$$
\frac{1}{n} b+a\left(1-\gamma \sigma^{2}\right)<c<a\left(1-\gamma \sigma^{2}\right)+b
$$

The new pre-treatment condition for a cooperative choice is

$$
c<\frac{1}{n} b+a\left(1-\gamma \sigma^{2}\right)
$$

We now consider our Label treatment and assume that it eliminates consumers' perception of informational asymmetry about the responsible characteristics of the chosen products. Consider as well that, since our base label treatment does not provide specific information but works on persuasion and perceptions, we remain within the green nudging case. As a consequence, the post-treatment condition for a cooperative choice becomes

$$
c<\frac{1}{n} b+a
$$

(A2') is slightly easier to achieve than (A2)so that, after the treatment is introduced, some consumers may find it optimal to switch to the purchase of the green product. Note as well that, according to this modified version of the base model, a significant change in the cooperative choice induced by the treatment not only implies that the treatment eliminates (or significantly reduces) the informational asymmetry, but also that $a>0$ or that consumers have nonzero other-regarding preferences. Hence, the presence of other-regarding preferences is a necessary condition for the significance of the treatment under this specific version of the model. 
A second modified version of the model can be considered by including the presence of a reciprocity argument where the value of the cooperative choice is function of the number of cooperators. As is well known (Rabin, 1987), reciprocity implies that players have a disutility in cooperating the larger the number of people who cooperate and viceversa. In this second modified version pre-treatment payoffs of the different strategies are as follows Cooperation: $\left(\frac{E(j)+1}{n}\right) b+a\left(1-\gamma \sigma^{2}\right)-c+r E(j)$ Non cooperation $\frac{E(j)}{n} b+a\left(1-\gamma \sigma^{2}\right)$ where $r E(j)$ is the positive reciprocity effect that is function of the number of cooperators. As a result the pre-treatment cooperation condition becomes

$$
c<\frac{1}{n} b+a\left(1-\gamma \sigma^{2}\right)+r E(j)
$$

Under this version of the model augmented with reciprocity arguments post treatment payoffs become Cooperation: $\frac{E\left(j+d_{j}(T)\right)+1}{n} b+a-c+r E\left(j+d_{j}(T)\right)$ Non cooperation $\frac{E\left(j+d_{j}(T)\right)}{n} b+a$ where $d_{j}(T)$ is the player $j$ 's expected change in the number of cooperators due to the treatment. $d_{j}(T)$ may be different from zero either because the consumer assumes that other consumers have ex ante strong asymmetric information on product characteristics and/or that the latter assume that other consumers have (second order beliefs) in presence of a reciprocity argument.

The post-treatment cooperation condition therefore turns into

$$
c<\frac{1}{n} b+a+r E\left(j+d_{j}(T)\right)
$$

with the reciprocity argument raising even more than in (A2) the probability of shifting to the cooperative strategy after the base label treatment (again under the necessary condition of the existence of other-regarding preferences either under the form of the component $A$ or of the same reciprocity argument).

To conclude, the three versions of the model (base model, augmented with asymmetric information on product characteristics, augmented with asymmetric information on product characteristics and reciprocity effect) show that, for products for which the connection with health is excluded, the base label treatment may have a positive and significant impact on the choice of the cooperative strategy (that is, the choice of the responsible products advertised with the shelf poster): i) only in presence of a nonzero other-regarding component combined with asymmetric information on product characteristics ii) and/or a reciprocity argument with expectation that the shelf poster will increase the number of cooperators. The simple presence of other-regarding components without asymmetric information and/or reciprocity argument is not sufficient per se to produce a significant post-treatment effect since, in that case, we are back to the base model and nothing changes after the treatment on the area of the Prisoner's dilemma and the inequality ruling the cooperation condition. Note as well that the same theoretical framework may be used to evaluate the effect of the label plus price increase treatment. In such case we must add to the framework the impact of the change in the price difference between the conventional and the responsible product taking into account the 5 or 10 percent increase of the latter. This effect just raises (i.e., $c$ ) in the model thereby making more difficult the conditions for the responsible choice.

Considering what developed above, the $x_{j t}$ vector of observed good characteristics when choosing the responsible product in the Nevo specification under the base vote with the wallet model (section 3.1) includes $\frac{1}{n} b+a-c$ that is, a quantity measuring the change in utility arising when shifting from the conventional to the VV green product. This characteristics is unmodified by the experiment. If, on the contrary, we are in the (second modified) asymmetric information framework the base characteristics is $(1 / n) b+a\left[1-\gamma \sigma^{2}\right]-c$ before treatment and $(1 / n) b+a-c$ 
after treatment with the treatment raising the utility of choosing the responsible product by $a \gamma \sigma^{2}$. Under the (third modified) asymmetric information plus reciprocity version of the model the pretreatment characteristics is $\frac{1}{n} b+a\left[1-\gamma \sigma^{2}\right]+r E(j)-c$, while the post-treatment characteristics $\frac{1}{n} b+a\left[1-\gamma \sigma^{2}\right]+r E\left(j+d_{j}(T)\right)-c$. Hence the treatment raises the utility of choosing the responsible product by $a \gamma \sigma^{2}+r E\left(d_{j}(T)\right)$. 